\title{
Classification of tree species using high-resolution QuickBird-2 satellite images in the valley of Ui-dong in Bukhansan National Park
}

\author{
Hye-Mi Choi and Keum-Chul Yang* \\ Department of Civil and Environmental Engineering, Kongju National University, Cheonan 330-717, Korea
}

\begin{abstract}
This study was performed in order to suggest the possibility of tree species classification using high-resolution QuickBird-2 images spectral characteristics comparison(digital numbers [DNs]) of tree species, tree species classification, and accuracy verification. In October 2010, the tree species of three conifers and eight broad-leaved trees were examined in the areas studied. The spectral characteristics of each species were observed, and the study area was classified by image classification. The results were as follows: Panchromatic and multi-spectral band 4 was found to be useful for tree species classification. DNs values of conifers were lower than broad-leaved trees. Vegetation indices such as normalized difference vegetation index (NDVI), soil brightness index (SBI), green vegetation index (GVI) and Biband showed similar patterns to band 4 and panchromatic (PAN); Tukey's multiple comparison test was significant among tree species. However, tree species within the same genus, such as Pinus densiflora-P. rigida and Quercus mongolica-Q. serrata, showed similar DNs patterns and, therefore, supervised classification results were difficult to distinguish within the same genus; Random selection of validation pixels showed an overall classification accuracy of $74.1 \%$ and Kappa coefficient was $70.6 \%$. The classification accuracy of Pterocarya stenoptera, $89.5 \%$, was found to be the highest. The classification accuracy of broadleaved trees was lower than expected, ranging from $47.9 \%$ to $88.9 \%$. P. densiflora-P. rigida and Q. mongolica-Q. serrata were classified as the same species because they did not show significant differences in terms of spectral patterns.
\end{abstract}

Key words: QuickBird, spectral characteristics, tree species classification, vegetation index

\section{INTRODUCTION}

Forests account for over $60 \%$ of land area in South Korea. However, city expansion plans and urban development projects have inevitably created more demands and increasing forest development. The Ministry of Environment (ME)'s latest report on the time-series changes in the land cover map of the country shows significantly reduced forest area: approximately $64 \%$ remained as of the end of 2000s from $66 \%$ at the end of the 1980s (Ministry of Environment 2010).

Forests, as resources for human activities and wild life habitat, play an indispensible role in the environment and in the entire ecosystem. They require an organized system of forest survey and management to prevent damages by indiscriminate development.

The 1st National Natural Environment Survey kicked off in 1986, as part of ME's nationwide natural environment survey (as per Article 32 of the National Environment Conservation Act) initiative to be carried out every 10 years. From the 2nd National Natural Environment Survey onwards, results and information collected were

\section{Open Access http://dx.doi.org/10.5141/JEFB.2012.013}

This is an Open Access article distributed under the terms of the Creative Commons Attribution Non-Commercial License (http://creativecommons. org/licenses/by-nc/3.0/) which permits unrestricted non-commercial use distribution, and reproduction in any medium, provided the original work is properly cited.
Received 25 October 2011, Accepted 02 March 2012

*Corresponding Author

E-mail: yangkc@kongju.ac.kr

Tel: +82-41-521-9311 
included in the GIS-DB building and then generated into an official report on the status of the eco-environment (published in April, 2007). Over $90 \%$ of the report concerns the results of the vegetation survey, in addition to covering various aspects of the ecosystem, including information on the flora and the fauna (mammals, birds, amphibians and reptiles, insects, freshwater fish, and freshwater invertebrates) and topography (National Institute of Environmental Research 2010).

With the 2013 4th National Natural Environment Survey, the survey interval is to be reduced to 5 years, rather than the aforementioned 10. Thus, devising an efficient vegetation survey master plan has become a matter of urgency, in anticipation of the significant increase in vegetation survey area to be covered annually.

Satellites have the merit of being able to obtain data for a large area. Since 1995, several countries have launched satellites that can obtain images with spatial resolution of equal to or less than $10 \mathrm{~m}$. In addition, the QuickBird, launched October 2001, is a high-resolution satellite from Digital Globe. It offers high spatial resolution by simultaneously acquiring $0.64-\mathrm{m}$ panchromatic (PAN) and 2.50$\mathrm{m}$ multispectral imageries and has four bands that simultaneously record reflected or emitted radiation from the earth's surface in the blue (band $1,0.45$ to $0.52 \mu \mathrm{m}$ ), green (band 2, 0.52 to $0.60 \mu \mathrm{m}$ ), red (band 3, 0.63 to $0.69 \mu \mathrm{m}$ ) and near-infrared (band $4,0.76$ to $0.90 \mu \mathrm{m}$ ) portions of the electromagnetic spectrum.

Forest classification is important for forest ecosystem management and scientific research. Field ground surveys of plant species composition and forest classification are time consuming and provide incomplete information of forest polygon delineation. The techniques of plant species classification, from satellites with high resolution images, could be the most effective way to classify and assess large areas of forest (Martin et al. 1998, Franklin et al. 2001).

Studies using IKONOS and QuickBird images have been used to identify trees (Ham et al. 2004, Katoh 2004, Kim 2008) and classify forest types (Chung et al. 2001, Lee 2001, Jayakumar et al. 2007) in forest stands with discernible crown diameter. However, it is difficult to distinguish among species in broadleaved forests, as they have the same tone in QuickBird images. The classification process of high resolution images, using spectral characteristics of bands and vegetative indices, needs to be developed.

Therefore, the objectives of this study are to use the high-resolution QuickBird-2 satellite images to compare and analyze the spectral characteristics of the tree species within the study area, to automatically classify and perform an accuracy assessment of the tree species, using the images, and to address the question of feasibility of QuickBird-2 imagery-based tree species classification by providing the relevant databases.

\section{MATERIALS AND METHODS}

\section{Study site}

The study area was defined as the $122,500 \mathrm{~m}^{2}(350 \mathrm{~m} \times$ $350 \mathrm{~m}$ ) land located at $127^{\circ} 00^{\prime} 00^{\prime \prime} \mathrm{E}-127^{\circ} 00^{\prime} 15^{\prime \prime}$ E longitude and $37^{\circ} 40^{\prime} 35^{\prime \prime} \mathrm{N}-37^{\circ} 40^{\prime} 50^{\prime \prime} \mathrm{N}$ latitude from the Bukhansan National Park office at Ui-dong, Gangbuk-gu, Seoul, Korea (Fig. 1). The study forest is composed of broadleaved trees such as Quercus mongolica, Q. serrata, the coniferous tree Pinus densiflora, and the Robinia pseudoacacia plantation. The altitude ranges from 193 to $304 \mathrm{~m}$ above mean sea level. The study area includes steep slopes $(63 \%)$ and gentle ones. The mean annual precipitation is $1,450.5 \mathrm{~mm}$, and the mean annual temperature is $12.5^{\circ} \mathrm{C}$. Table 1 was showed tree species condition in this study.

\section{Materials}

Satellite images obtained from Digital Globe's QuickBird-2 were used as primary data for this study. These offer spatial resolution by simultaneously acquiring $0.64-\mathrm{m}$ PAN and 2.50-m multispectral imageries. There are four bands that simultaneously record reflected or emitted radiation from the earth's surface in the blue (band 1, 0.45 to $0.52 \mu \mathrm{m}$ ), green (band 2, 0.52 to $0.60 \mu \mathrm{m}$ ), red (band 3,

Table 1. Tree species conditions in the study, and their abbreviations

\begin{tabular}{|c|c|c|c|}
\hline Species (abbreviation) & $\begin{array}{l}\mathrm{DBH} \\
(\mathrm{cm})\end{array}$ & $\begin{array}{l}\text { CD } \\
(\mathrm{m})\end{array}$ & $\begin{array}{c}\text { Sample } \\
\text { No. }\end{array}$ \\
\hline Larix leptolepis (Ll) & 35 & 5.9 & 1 \\
\hline Pinus densiflora $(\mathrm{Pd})$ & $26.9-49.9$ & 4.9-10.7 & 8 \\
\hline Pinus rigida $(\mathrm{Pr})$ & $25.3-42$ & $4.0-7.3$ & 7 \\
\hline Alnus hirsuta (Alh) & $24.8-58.1$ & $5.1-6.6$ & 2 \\
\hline Prunus sargentii (Prs) & $22.6-97.8$ & $5.3-13.5$ & 6 \\
\hline Pterocarya stenoptera (Pts) & $39-49.8$ & 8.9 & 1 \\
\hline Quercus acutissima (Qa) & $45.5-55.2$ & 5.5 & 1 \\
\hline Quercus aliena (Qal) & $29.1-90.2$ & $5.9-9.9$ & 3 \\
\hline Quercus mongolica (Qm) & $42.7-124.6$ & 4.6-12.6 & 10 \\
\hline Quercus serrata (Qs) & $33.1-108.2$ & $4.2-8.6$ & 9 \\
\hline Robinia pseudoacacia (Rop) & $15.3-62.3$ & 3.9-6.3 & 8 \\
\hline
\end{tabular}

$\mathrm{DBH}$, diameter at breast height; $\mathrm{CD}$, crown diameter. 


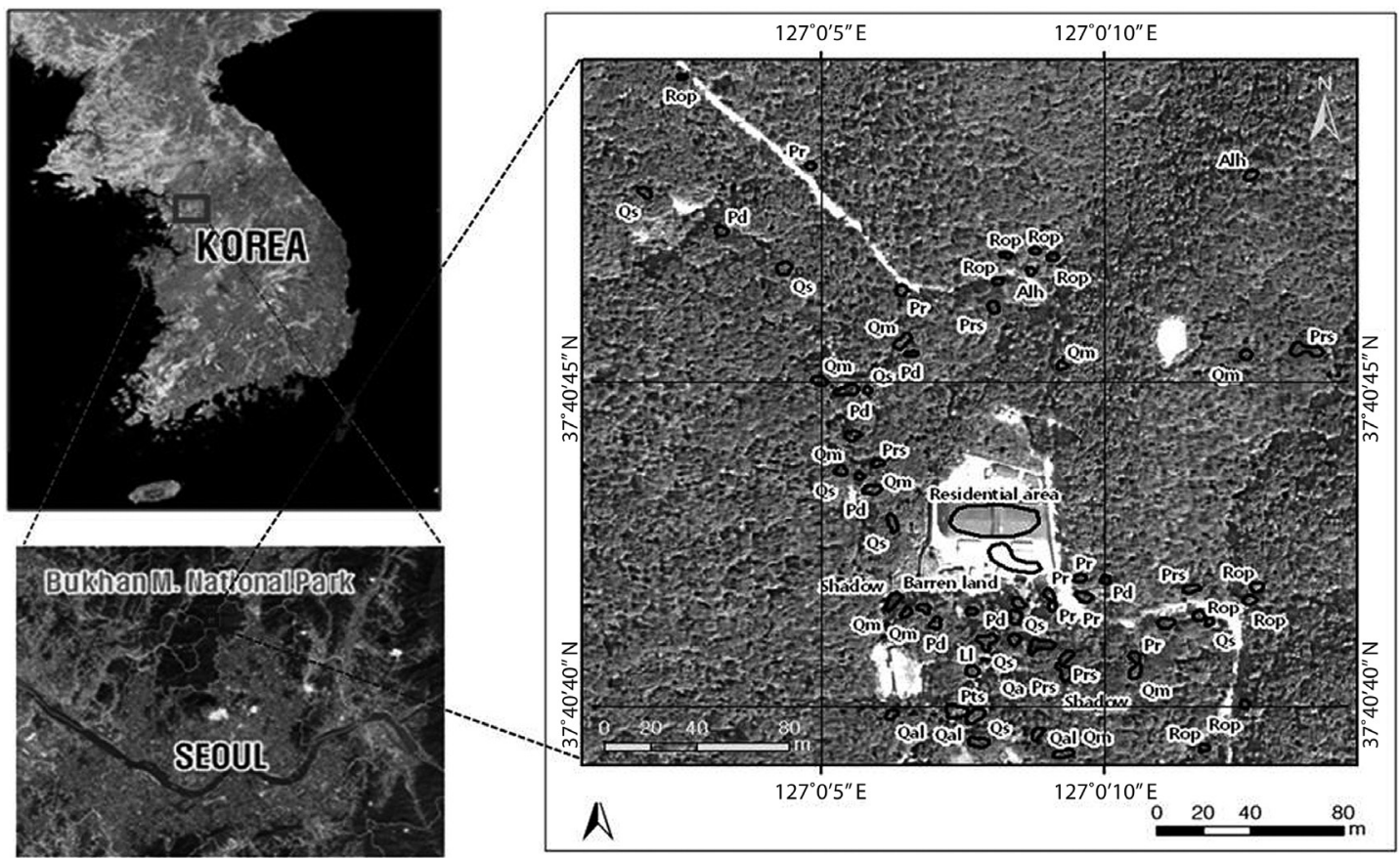

Fig. 1. Map of the study area in Ui-dong valley in Seoul and training data of tree crowns derived from field survey on QuickBird PAN image. LI, Larix leptolepis; Pd, Pinus densiflora; Pr, Pinus rigida; Alh, Alnus hirsute; Prs, Prunus sargentii; Pts, Pterocarya stenoptera; Qa, Quercus acutissima; Qal, Quercus aliena; Qm, Quercus mongolica; Qs, Quercus serrata; Rop, Robinia pseudoacacia.

0.63 to $0.69 \mu \mathrm{m}$ ) and near-infrared (band $4,0.76$ to 0.90 $\mu \mathrm{m})$ portions of the electromagnetic spectrum. The digital map, detail vegetation map, and boundary data of the Bukhan Mountain National Park were obtained at the courtesy of relevant institutions and authorities, and the digital elevation model (DEM) was produced hands-on, using the digital map for this particular study (Table 2).

\section{Methods}

The study was carried out in 3 major parts: field survey, image processing, and tree species analysis. Refer to Fig. 2 for a study process flow chart.

The site map, produced from QuickBird-2 images, was used to carry out the field survey. The diameter at breast height $(\mathrm{DBH})$ and the crown diameter of the tree species were measured, and the crown boundary was marked on the map, scanned, and geometrically corrected to build the GIS-DB with the crown boundary, DBH, and crown diameter information for each tree species.

For image processing, rational polynomial coefficient data was provided at the purchase of images and was reflected to remove internal errors. Ground control point and DEM were each marked and built on a digital map with a ratio scale of 1:5,000 for orthography correction of PAN (resolution $0.64 \mathrm{M}$ ) and multispectral (resolution 2.50M) QuickBird images.

Field survey results were used to compare and analyze the band patterns of the orthography-corrected images and the spectral characteristics of each vegetation index.

Table 2. List of materials used in the study

\begin{tabular}{clll}
\hline & \multicolumn{1}{c}{ Data name } & Production & \multicolumn{1}{c}{ Data source } \\
\hline Raster & QuickBird-2 satellite Imagery & Sep 2008 & Digital Globe \\
Raster & Digital elevation model (DEM) & Oct 2010 & Directly produce \\
Vector & Digital map & May 2007 & National Geographic Information Institute \\
Vector & Detail vegetation map & $2008-2010$ & National Institute of Environmental Research \\
Vector & Boundary data of Bukhan Mountain National Park & 2010 & Ministry of Environment \\
\hline
\end{tabular}




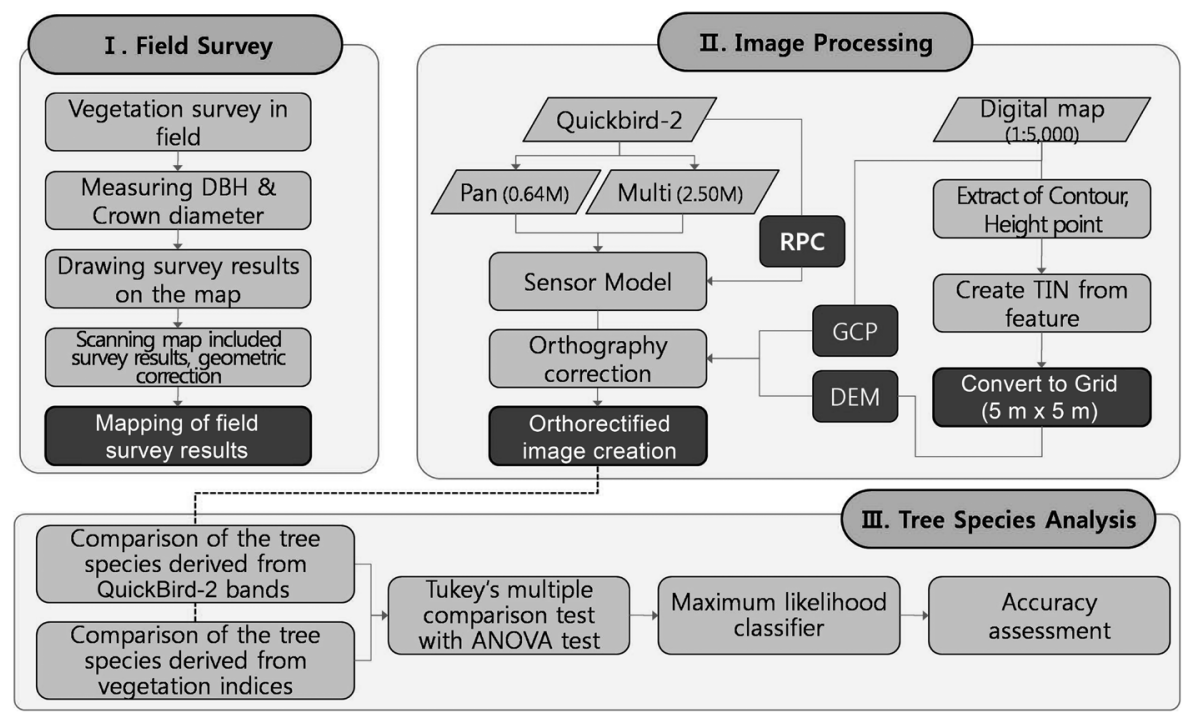

Fig. 2. Flow chart of the study. DBH, diameter at breast height; RPC, rational polynomial coefficient, GCP, ground control point, DEM, digital elevation model.

Tukey's multiple comparison tests were performed for a statistical significance assessment, and corresponding band combinations for tree species classification were set. Supervised classification, using the maximum likelihood classifier, was applied to the field survey area designated as the training region.

The final stage of the study consisted of comparing the results of supervised classification against the field survey findings for the final accuracy assessment necessary for

Table 3. Transformation of vegetation indices

\begin{tabular}{|c|c|}
\hline Vegetation index & Equation \\
\hline Biband'* & Band4/Band3 \\
\hline $\mathrm{NDVI}^{+}$ & {$[($Band $4-$ Band3 $) /($ Band $4+$ Band 3$)] \times 1,000$} \\
\hline $\mathrm{TNDV}^{\prime \ddagger}$ & {$\left[(\mathrm{NDVI}+0.5)^{1 / 2}\right] \times 100$} \\
\hline $\mathrm{SBI}^{\prime s}$ & $\begin{array}{l}0.326 \times \text { Band } 1+0.509 \times \text { Band } 2+0.560 \times \\
\text { Band } 3+0.567 \times \text { Band } 4\end{array}$ \\
\hline GVI' & $\begin{array}{l}{[-0.311 \times \text { Band } 1-0.356 \times \text { Band } 2-0.325 \times} \\
\text { Band } 3+0.819 \times \text { Band } 4]+200\end{array}$ \\
\hline $\mathrm{YVI}^{\prime * *}$ & $\begin{array}{l}{[-0.612 \times \text { Band } 1-0.312 \times \text { Band } 2+0.722 \times} \\
\text { Band3 }-0.081 \times \text { Band } 4]+1,000\end{array}$ \\
\hline $\mathrm{WBI}^{\prime+\dagger}$ & $\begin{array}{l}{[-0.650 \times \text { Band } 1+0.719 \times \text { Band } 2-0.243 \times} \\
\text { Band } 3-0.031 \times \text { Band } 4]+100\end{array}$ \\
\hline
\end{tabular}

"Ratio vegetation index (Jordan, 1969).

${ }^{\dagger}$ Normalized difference vegetation index (Kriegler et al. 1969).

†Transformation normalized difference vegetation index.

${ }^{5}$ Soil brightness index.

"Green vegetation index.

"*ellow stuff vegetation index.

${ }^{+\dagger}$ Water band index. determining the feasibility of image-based tree species classification and its proposal.

Programs used for this study included: Arcview 3.2 and ArcGIS 9.2 for DEM construction; ERDAS 9.1 for image processing (ERDAS 1997). Also, QuickBird-2 images were used to produce and analyze a total of 7 vegetation indices (Table 3).

\section{Statistical analysis}

Analysis of variance (ANOVA) was used to test for statistically significant differences among groups, using SPSS ver. 17.0 (SPSS Inc., Chicago, IL, USA), and Tukey's multiple comparison test was then used $(P<0.001)$, as shown in Table 4 . The classification accuracy was examined from a random selection of 800 pixels.

\section{RESULTS AND DISCUSSION}

\section{Comparison of the tree species derived from QuickBird-2 bands}

QuickBird-2 band analysis show lower digital numbers (DNs) for conifers, Pinus densiflora and P. rigida, than broad-leaved trees in Band 4. This is consistent with the previous image-based study findings of Landsat TM (Katoh 1988, 1995) and IKONOS (Katoh, 2004) conifers showed lower DNs than wide-leaved trees. On the contrast, Larix leptolepis, though a conifer, showed similar or 
higher DNs to wide-leaved trees. Such observations may be attributable to L. leptolepis which, being a deciduous conifer, was already showing a similar range of DNs at the time the images were taken in September (Fig. 3).

\section{Comparison of the tree species derived from vegetation indices}

A comparison of vegetation indices-based tree species spectral characteristics showed clear differences in the average DNs between tree species in the normalized

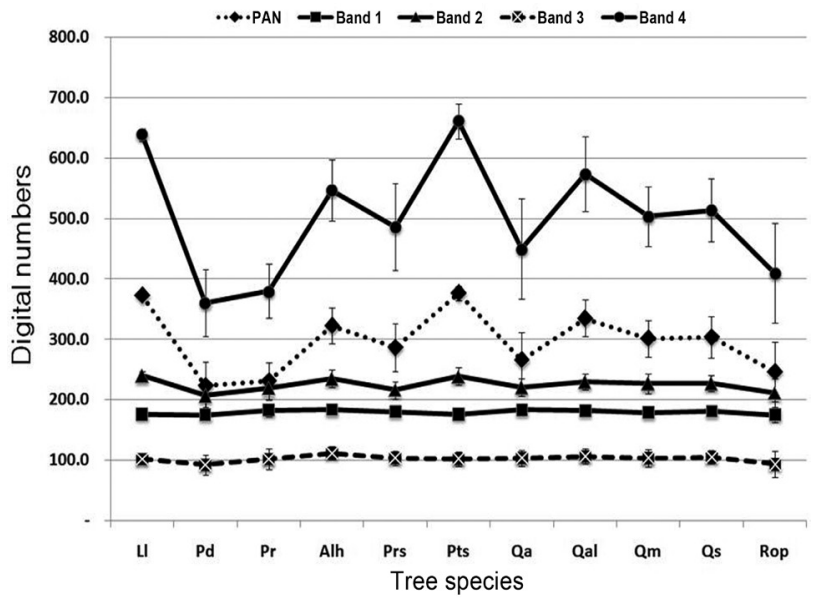

Fig. 3. Comparison of digital numbers values of tree species derived from QuickBird bands. PAN, panchromatic; LI, Larix leptolepis; Pd, Pinus densiflora; Pr, Pinus rigida; Alh, Alnus hirsute; Prs, Prunus sargentii; Pts, Pterocarya stenoptera; Qa, Quercus acutissima; Qal, Quercus aliena; Qm, Quercus mongolica; Qs, Quercus serrata; Rop, Robinia pseudoacacia. difference vegetation index (NDVI), green vegetation index (GVI), soil brightness index (SBI) and Biband. Such a distribution pattern was similar to the one obtained from image band spectral characteristics comparison (Fig. 4).

\section{Statistical significance assessment}

Tree species were classified into $a$ - $h$ groups, according to their spectral characteristics (Table 4). The group of trees with high DNs was designated as $e, f, g$ and $h$. Otherwise, the group with low DNs was depicted as $a$ and $b$.

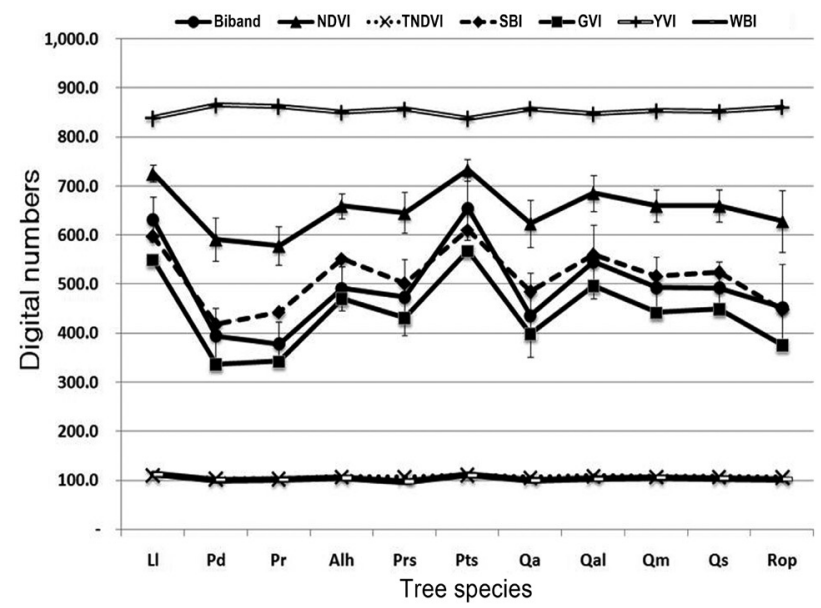

Fig. 4. Comparison of digital numbers values of tree species derived from vegetation indices. NDVI, normalized difference vegetation index; TNDVI, transformation NDVI; SBI, soil brightness index; GVI, green vegetation index; $\mathrm{YVI}$, yellow stuff vegetation index; WBI, water band index; LI, Larix leptolepis; $\mathrm{Pd}$, Pinus densiflora; Pr, Pinus rigida; Alh, Alnus hirsute; Prs, Prunus sargentii; Pts, Pterocarya stenoptera; Qa, Quercus acutissima; Qal, Quercus aliena; Qm, Quercus mongolica; Qs, Quercus serrata; Rop, Robinia pseudoacacia.

Table 4. Tukey's multiple comparison test of the QuickBird-2 bands and vegetation indices with ANOVA analysis $(N=1,450)$

\begin{tabular}{|c|c|c|c|c|c|c|c|c|c|c|c|c|}
\hline Species & PAN & Band 1 & Band 2 & Band 3 & Band 4 & Biband & NDVI & TNDVI & SBI & GVI & YVI & WBI \\
\hline Larix leptolepis & $\mathrm{g}$ & $\mathrm{ab}$ & $\mathrm{e}$ & $\mathrm{ab}$ & $\mathrm{h}$ & $\mathrm{f}$ & $\mathrm{e}$ & $\mathrm{E}$ & $\mathrm{g}$ & $\mathrm{f}$ & $\mathrm{a}$ & g \\
\hline Pinus densiflora & a & $\mathrm{a}$ & $\mathrm{a}$ & $\mathrm{a}$ & a & $\mathrm{ab}$ & $\mathrm{a}$ & A & a & $\mathrm{a}$ & $\mathrm{f}$ & bc \\
\hline Pinus rigida & a & bc & abcd & $\mathrm{ab}$ & $a b$ & $\mathrm{a}$ & $\mathrm{a}$ & A & a & $\mathrm{a}$ & $\mathrm{f}$ & bcd \\
\hline Alnus hirsuta & ef & $\mathrm{c}$ & $\mathrm{e}$ & $\mathrm{b}$ & fg & $\mathrm{d}$ & $\mathrm{cd}$ & $\mathrm{Cd}$ & ef & de & bc & ef \\
\hline Prunus sargentii & $\mathrm{cd}$ & $\mathrm{abc}$ & $\mathrm{abc}$ & $\mathrm{ab}$ & de & $\mathrm{cd}$ & $\mathrm{bc}$ & $\mathrm{Bc}$ & $\mathrm{cd}$ & $\mathrm{c}$ & de & $\mathrm{a}$ \\
\hline Pterocarya stenoptera & $\mathrm{g}$ & $\mathrm{ab}$ & $\mathrm{e}$ & $\mathrm{ab}$ & $\mathrm{h}$ & $\mathrm{f}$ & $\mathrm{e}$ & $\mathrm{E}$ & g & $\mathrm{f}$ & $\mathrm{a}$ & $\mathrm{g}$ \\
\hline Quercus acutissima & $\mathrm{bc}$ & $\mathrm{bc}$ & bcd & $\mathrm{ab}$ & $\mathrm{cd}$ & $\mathrm{bc}$ & $\mathrm{b}$ & $\mathrm{B}$ & $\mathrm{bc}$ & $\mathrm{b}$ & de & $\mathrm{ab}$ \\
\hline Quercus aliena & $\mathrm{f}$ & $a b c$ & de & $\mathrm{b}$ & g & e & $\mathrm{d}$ & $\mathrm{D}$ & $\mathrm{f}$ & $\mathrm{e}$ & $\mathrm{b}$ & cde \\
\hline Quercus mongolica & de & abc & cde & $\mathrm{ab}$ & ef & $\mathrm{d}$ & $\mathrm{cd}$ & $\mathrm{Cd}$ & cde & $\mathrm{cd}$ & $\mathrm{cd}$ & $\mathrm{f}$ \\
\hline Quercus serrata & de & $\mathrm{abc}$ & cde & $\mathrm{b}$ & ef & $\mathrm{d}$ & $\mathrm{cd}$ & $\mathrm{Cd}$ & def & $\mathrm{cd}$ & $\mathrm{c}$ & def \\
\hline Robinia pseudoacacia & $\mathrm{ab}$ & $\mathrm{a}$ & $\mathrm{ab}$ & $\mathrm{a}$ & bc & $\mathrm{cd}$ & $\mathrm{b}$ & $\mathrm{b}$ & $\mathrm{ab}$ & $\mathrm{b}$ & ef & bcd \\
\hline$F$ value & $167.8^{* * * x}$ & $14.7^{* * *}$ & $34.7^{* * * *}$ & $17.1^{* * * *}$ & $220.4^{* * s}$ & $110.0^{* * * *}$ & $211.2^{* * * *}$ & $103.6^{50 * t}$ & $139.6^{* * *}$ & $260.7^{* * * x}$ & $150.8^{* * * *}$ & $100.3^{* k+1}$ \\
\hline
\end{tabular}

**** $P<0.001$

PAN, panchromatic; NDVI, normalized difference vegetation index (Kriegler et al. 1969); TNDVI, transformation NDVI; SBI, soil brightness index; GVI, green vegetation index; YVI, yellow stuff vegetation index; WBI, water band index. 
Using the significant differences in the QuickBird bands (Table 4), the group with high DNs included Pterocarya stenoptera and L. leptolepis; the next group included Alnus hirsute, Prunus sargentii, Q. acutissima, Q. aliena, Q. mongolica, Q. serrata, R. pseudoacacia; and the group with the lowest DNs contained the conifers P. densiflora and $P$. rigida. For the vegetation indices (Table 4 ) that produced significant differences, $P$. stenoptera and L. leptolepis belonged to the group with high DNs; while P. densiflora and $P$. rigida belonged to the group with low DNs. The QuickBird-2 bands and vegetation indices produced similar groups.

A statistical significance assessment revealed variations in the spectral characteristics among tree species in the PAN, Band 4, Biband, NDVI, SBI, and GVI. However, species' signatures between $Q$. mongolica and Q. serrata were indistinguishable; both showed indiscernible differences in QuickBird images and in DNs values for spectral characteristics.

\section{Classification}

Based on the results of the statistical significance test, images of 5 QuickBird-2 bands and vegetation indices were collected and the maximum likelihood classifier was applied for automatic classification. Biband, however,

Table 5. Areas of each tree species in supervised classification

\begin{tabular}{lllr}
\hline & Family & Species & Area $\left(\mathbf{m}^{2}\right)$ \\
\hline Conifers & Pinaceae & Ll & 49.25 \\
& & Pd & $12,254.25$ \\
Broad-leaved & Betulaceae & Alh & $12,540.25$ \\
trees & Rosaceae & Prs & $19,678.50$ \\
& Juglandaceae & Pts & $5,975.25$ \\
& Fagaceae & Qa & 862.50 \\
& & Qal & $5,569.50$ \\
& & Qm & $10,339.75$ \\
& & Qs & $20,694.25$ \\
& & Rop & $13,914.25$ \\
Etc. & Fabaceae & Residential area & $12,962.75$ \\
& exception & Barren land & 934.25 \\
& & Shadow & $2,081.75$ \\
Total & & & $122,500.00$ \\
\hline
\end{tabular}

LI, Larix leptolepis; Pd, Pinus densiflora; Pr, Pinus rigida; Alh, Alnus hirsute; Prs, Prunus sargentii; Pts, Pterocarya stenoptera; Qa, Quercus acutissima; Qal, Quercus aliena; Qm, Quercus mongolica; Qs, Quercus serrata; Rop, Robinia pseudoacacia. was excluded from automatic classification in order to prevent potential errors because it failed to show normal distribution, despite optimal results in the statistical significance assessment.

Results of the classification, as shown in Fig. 5, revealed that the Quercus mongolica covered the largest area20,700 $\mathrm{m}^{2}$ (Table 5).

\section{Accuracy assessment}

An accuracy assessment showed an overall accuracy of $74.1 \%$. The three highest accuracy results were shown in Pterocarya stenoptera (89.5\%), Larix leptolepis (88.9\%), and the Prunus sargentii (74.4\%). However, in 2 cases, spectral patterns did not show significant differences even within the same genus, resulting in them being classified as the same species: between P. densiflora $(47.9 \%)$ and P. rigida (60.4\%), between $Q$, mongolica $(57.3 \%)$ and Q. serrata (56.0\%) (Table 6).

\section{CONCLUSION}

Using the results from a detailed vegetation survey, an area rich in tree species within the Bukhansan National Park was selected for tree species survey, QuickBird-2 image-based supervised classification, and accuracy assessment of the classification outcomes.

Results of the DNs value analysis of tree species showed that Band 4 and PAN images were useful for tree species classification using image bands. Conifers showed lower DNs values than broad-leaved trees in Band 4, with the exception of the Larix leptolepis, which showed otherwise. L. leptolepis, a deciduous conifer, may have already begun shading at the time the images were taken (September), showing similar DNs values as broad-leaved trees. The distribution of DNs values for each vegetation index was consistent with the differences/similarities in spectral characteristics obtained from image band observation.

A statistical significance assessment of tree species spectral characteristics, based on Tukey's test, showed similar spectral patterns among trees of the same genus, namely between Pinus densiflora and P. rigida, and between Quercus mongolica and Q. serrata. Hence, species differentiation was indiscrete.

Q. mongolica showed the largest distribution in supervised classification, followed by: Alnus hirsuta, Q. serrata, Robinia pseudoacacia, P. rigida, and the P. densiflora.

The study area for this research was limited to the Ui- 


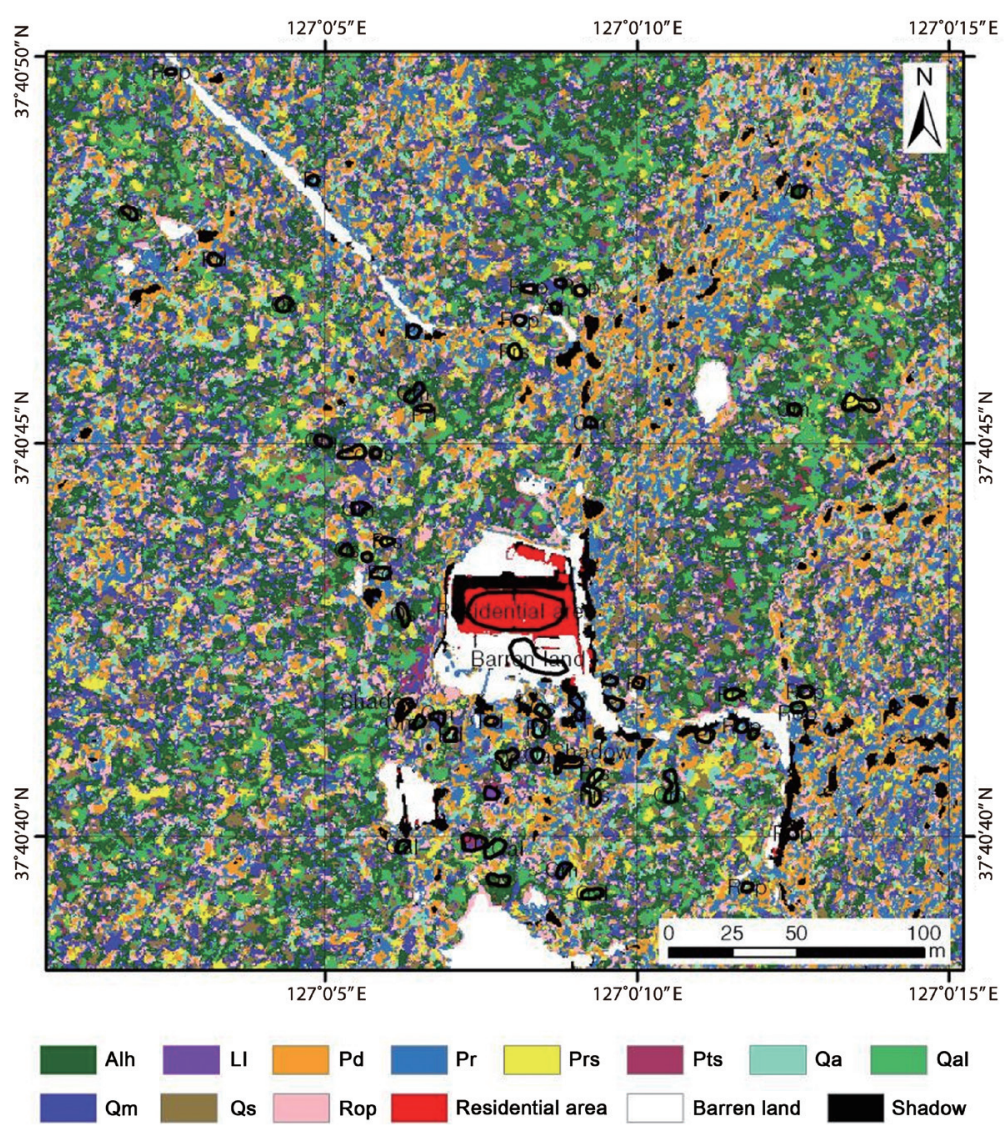

Fig. 5. Tree species classification map derived from QuickBird-2 data, with maximum likelihood classifier. Alh, Alnus hirsute; LI, Larix leptolepis; Pd, Pinus densiflora; Pr, Pinus rigida; Prs, Prunus sargentii; Pts, Pterocarya stenoptera; Qa, Quercus acutissima; Qal, Quercus aliena; Qm, Quercus mongolica; Qs, Quercus serrata; Rop, Robinia pseudoacacia.

Table 6. Accuracy assessment of randomly selected pixels

\begin{tabular}{|c|c|c|c|c|c|c|c|c|c|c|c|c|c|c|c|c|c|}
\hline & \multicolumn{14}{|c|}{ Field survey data } & \multirow{2}{*}{ - Total } & \multirow{2}{*}{$\begin{array}{c}\text { User's } \\
\text { accuracy } \\
(\%)\end{array}$} \\
\hline & & Alh & Ll & Pd & $\operatorname{Pr}$ & Prs & Pts & Qa & Qal & Qm & Qs & Rop & Etc. 1 & Etc.2 & Etc.3 & & \\
\hline \multirow{14}{*}{$\begin{array}{c}\text { QuickBird-2 } \\
\text { classification } \\
\text { data }\end{array}$} & Alh & 7 & & & & & & & & 5 & & & & & & 12 & 58.3 \\
\hline & $\mathrm{Ll}$ & & 8 & & & & 2 & & & 1 & & & & & & 11 & 72.7 \\
\hline & $\mathrm{Pd}$ & & & 34 & 14 & 2 & & 1 & & 3 & 6 & 12 & & & & 72 & 47.2 \\
\hline & $\operatorname{Pr}$ & & & 22 & 32 & 1 & & & & 1 & 1 & 2 & & 1 & 1 & 61 & 52.5 \\
\hline & Prs & & & 2 & 1 & 52 & & 2 & 2 & & 8 & 4 & & & & 71 & 73.2 \\
\hline & Pts & 1 & 1 & & & & 17 & & 1 & 6 & 1 & & & & & 27 & 63.0 \\
\hline & Qa & & & & & & & 4 & & & & & & & & 4 & 100.0 \\
\hline & Qal & 1 & & & & 5 & & & 22 & 5 & & 1 & & & & 34 & 64.7 \\
\hline & Qm & 3 & & 1 & & 2 & & & 7 & 51 & 18 & 4 & & & & 86 & 59.3 \\
\hline & Qs & 1 & & & & 3 & & 1 & 3 & 10 & 47 & 1 & & & & 66 & 71.2 \\
\hline & Rop & 1 & & 5 & 4 & 4 & & & & 7 & 3 & 33 & & 1 & 1 & 59 & 55.9 \\
\hline & Etc. 1 & & & & 2 & & & & & & & & 198 & & 1 & 201 & 98.5 \\
\hline & Etc. 2 & & & & & & & & & & & & & 58 & & 58 & 100.0 \\
\hline & Etc.3 & & & 7 & & & & & & & & 1 & & & 30 & 38 & 78.9 \\
\hline Total & & 14 & 9 & 71 & 53 & 69 & 19 & 8 & 35 & 89 & 84 & 58 & 198 & 60 & 33 & 800 & 71.1 \\
\hline \multicolumn{2}{|c|}{ Producer's accuracy (\%) } & 50.0 & 88.9 & 47.9 & 60.4 & 75.4 & 89.5 & 50.0 & 62.9 & 57.3 & 56.0 & 56.9 & 100.0 & 96.7 & 90.9 & 70.2 & 74.1 \\
\hline
\end{tabular}

Etc.1, residential area; Etc.2, barren land; Etc.3, shadow.

Alh, Alnus hirsute; LI, Larix leptolepis; Pd, Pinus densiflora; Pr, Pinus rigida; Prs, Prunus sargentii; Pts, Pterocarya stenoptera; Qa, Quercus acutissima; Qal, Quercus aliena; Qm, Quercus mongolica; Qs, Quercus serrata; Rop, Robinia pseudoacacia. 
dong valley region and, thus, inevitable restrictions were imposed; a limited number of tree species, geographical signatures of the study area, and the season images were obtained, as variables in the study, and these were prone to affect the spectral characteristics of the tree species. Monthly or "all-season" image analysis in multiple areas is recommended for more reliable results.

\section{LITERATURE CITED}

Chung KH, Lee WK, Lee JH, Kim KH, Lee SH. 2001. Classification of forest type using resolution imagery of satellite IKONOS. Korean J Remote Sens 17: 275-284. (in Korean with English summary)

ERDAS. 1997. ERDAS Field Guide. 4th ed. ERDAS, Atlanta, GA.

Franklin SE, Maudie AJ, Lavigne MB. 2001. Using spatial cooccurrence texture to increase forest structure and species composition classification accuracy. Photogramm Eng Remote Sens 67: 849-855.

Ham BY, Lee WK, Chong JS, Lee JH. 2004. Estimation of spatial distribution and occurrence probability of oak species using IKONOS satellite imagery and GIS. Korean J For Meas 7: 74-84. (in Korean with English summary)

Jayakumar S, Ramachandran A, Lee JB, Heo J. 2007. Objectoriented classification and QuickBird multi-spectral imagery in forest density mapping. Korean J Remote Sens 23: $153-160$.

Jordan CF. 1969. Derivation of leaf-area index from quality of light on the forest floor. Ecology 50: 663-666.

Katoh M. 1988. Estimation of rates of the crown area in yezo spruce plantations with Landsat thematic mapper data.
Proceedings of the 16th ISPRS/IUFRO, Kyoto, pp 23-29.

Katoh M. 1995. The estimation of crown densities in todomatsu plantations using Landsat thematic mapper data. Proceedings and IUFRO on sustainable forest management, 1995 Oct 17-21, Hokkaido, pp 246-253.

Katoh M. 2004. Classifying tree species in a northern mixed forest using high-resolution IKONOS data. J For Res 9: 7-14.

Kim C. 2008. Use of crown feature analysis to separate the two pine species in QuickBird imagery. Korean J Remote Sens 24: 267-272.

Kriegler FJ, Malila WA, Nalepka RF, Richardson W. 1969. Preprocessing transformations and their effects on multispectral recognition. Proceedings of the 6th International Symposium on Remote Sensing of Environment, 1969 Oct 13-16, University of Michigan, Ann Arbor, MI, pp 97-131.

Lee JH. 2001. A study on classification and spatial distribution of forest types using IKONOS satellite imagery and GIS. MS Thesis. Korea University, Seoul, Korea. (in Korean with English summary)

Martin ME, Newman SD, Aber JD, Congalton RG. 1998. Determining forest species composition using high spectral resolution remote sensing data. Remote Sens Environ 65: 249-254.

Ministry of Environment. 2010. Mapping of the Detailedclass Land Cover Map Using Satellite Images. Report. Ministry of Environment, Gwacheon.

National Institute of Environmental Research. 2010. Construction of GIS-DB for National Ecosystem Information. Report. National Institute of Environmental Research, Incheon. 